\title{
Algunas consideraciones sobre el arte en México en las décadas de 1990 y 2000
}

Some Thoughts on Contemporary Art in Mexico from the 1990s and 2000s

\section{IRMGARD EMMELHAINZ}

INVESTIGADORA INDEPENDIENTE (MEXICO) iemmel@hotmail.com

Escritora, traductora, investigadora y docente. En 2012, la BUAP (Benemérita Universidad Autónoma de Puebla) publicó su libro de ensayos: Alotropías en la trinchera evanescente: estética y geopolítica en la era de la guerra total. Ha sido invitada a impartir seminarios, conferencias y cursos a universidades y plataformas prestigiosas a nivel internacional. Su trabajo ha sido traducido al alemán, italiano, noruego, serbio, inglés, francés, árabe, español y hebreo para catálogos, revistas y journals especializados sobre cine, arte, política y cultura. Su libro: La tiranía del sentido común: la reconversión neoliberal de México fue publicado en 2016 con un prólogo de Franco Berardi (Bifo).

RESUMEN: En los últimos 25 años, una forma distinta de hacer, exhibir y circular arte en México se incorporó a la economía global con ayuda de fondos públicos y privados. El arte en México de los 1990s y 2000s abarca la transición de una reflexión sobre las promesas rotas de la modernidad desde un punto de vista periférico, y un desafío a la hueca imagen de mexicanidad y su institucionalización, a lo que se conoce como "arte contemporáneo". La liberalización del mercado llegó de la mano con la liberalización de la identidad, construcciones históricas y la hibridez-pastiche mestiza de lo postmoderno, dando lugar a una veta en la producción artística que exploró las condiciones precarias de trabajo en la periferia. La espacialidad de la ciudad, o más bien, un sentido de sitio comenzó a ganar relevancia, un sitio sin embargo indeterminado, dislocado y experimentado subjetivamente.

Palabras Clave: Arte contemporáneo, globalización, arte en México, neoliberalismo, autonomía, política, mexicanismo, modernismo y postmodernismo
ABSTRACT: In the past 25 years, a different way of making, exhibiting, showing and circulating art in Mexico was incorporated to the global economy with the help of private and public funds. Art in Mexico from the 1990s and 2000s encompasses a transition from a reflection on the broken promises of modernity from a peripheral point of view, and a challenge to the shallow image of mexicanidad and its institutionalization, to what is known as "contemporary art." The liberalization of the market came hand in hand with the liberalization of identity, historical constructions and the pastiche-like and mestizo hybridity of postmodernity, giving leeway to a vein in art production that explored the precarious conditions of labor in the periphery. The spatiality of the city, or rather, a sense of site began to gain relevance, a site that is however indeterminate, dislocated and experienced subjectively. In this context, the potential of the city was exploited as epistemic space and thus as a rich carrier of sensible knowledge.

KEY WORDS: Contemporary art, globalization, art in Mexico, Neoliberalism, autonomy, politics, mexicanismo, modernism and postmodernism.

Emmelhainz, Irmgard “Algunas consideraciones sobre el arte en México en las décadas de 1990 y $2000 ”$.

Kamchatka. Revista de análisis cultural 7 (Junio 2016): 281-305

DOI: 10.7203/KAM.7.6804 ISSN: 2340-1869 
Irmgard Emmelhainz. Algunas consideraciones sobre el arte en México...

Durante la última década, en la producción cultural mexicana se consolidó una alianza entre Estado, corporaciones, iniciativa privada y mercado del arte $^{1}$. Esta alianza se concretó una vez que el arte mexicano se había internacionalizado, proliferado y adquirido importancia global, fenómenos que comenzaron a gestarse en la década de 1990. La expansión y relevancia que cobró el arte mexicano estuvieron directamente relacionadas con la expansión global de un lenguaje estético europeo y norteamericano anclado en la herencia del arte conceptual y minimalista de las décadas de 60 y 70 . En el contexto mexicano, este lenguaje estuvo vinculado a cambios violentos y agitación social producto de las políticas neoliberales y de los procesos socioeconómicos globales inherentes al nuevo orden mundial. Otra de las razones fue que las fronteras resultaron sumamente porosas en lo que respecta al intercambio cultural, y por eso, el arte "mexicano" fue diseminado y es ahora producido y expuesto en todo el mundo. Esta desterritorialización del arte y los artistas es un signo de la condición "postconceptual" del arte contemporáneo, la cual implica para Peter Osborne la proliferación de los discursos de lo moderno, un vaciamiento del concepto de posmodernidad como categoría crítica y temporal, y su sustitución por una modernidad global singular, diferenciada complejamente en su interior (Osborne, 2014: 19).

En ese sentido, podríamos pensar el arte contemporáneo como el sitio en el cual las historias del presente de varias partes del mundo se confrontan simultáneamente para delibrar un intento por comprender el presente por medio de una reducción temporal y una condensación espacial (Kwon, 2009: 17). Teniendo en cuenta la desterritorialización y diseminación del arte "mexicano", la preocupación de los artistas por descifrar el presente global moldeado por las políticas neoliberales, y que al arte contemporáneo se le considera una herramienta para lograr mejora y desarrollo, en este trabajo se elucidará cómo el arte en y de México, durante las décadas de 1990 y los 2000, encarnó la transición de una reflexión sobre las promesas rotas de la modernidad desde un punto de vista periférico, aunada al desafío a la imagen hueca de la mexicanidad y su institucionalización, a la incorporación del arte mexicano a la economía global con la ayuda de fondos públicos y privados, habiendo institucionalizado y mercantilizado el modelo de la ruptura ${ }^{2}$.

Para iniciar una consideración del arte mexicano a partir del momento en que se inauguró una nueva etapa histórica en 1989 -cuando cayó el régimen soviético-, podríamos empezar con $U n$ banquete en Tetlapayac (2000), película experimental de Olivier Debroise que resume las

\footnotetext{
1 Agradezco a Jimena Acosta, Tatiana Cuevas Pip Day, Silvia Gruner, Damián Ortega y Miguel Ventura sus generosas lecturas de versiones tempranas de este texto. Una parte del texto fue traducida del inglés por Natalia Magdaleno López. Estoy agradecida también con el brillante ojo editor de Nadia Benavides Méndez.

${ }^{2}$ Con modelo de la ruptura me refiero al generado por la generación de artistas mexicanos y extranjeros que en los años 50s hicieron obra reaccionando contra los valores percibidos como desgastados de los muralistas mexicanos. Sus valores eran cosmopolitas, abstractos y apolíticas, buscando trascender el muralismo y a las instituciones culturales que habían oficializado sus aspectos formales e ideológicos traducidos a lo que se conoce como mexicanidad..
} 
preocupaciones y sensibilidades de la escena artística mexicana en la década de los 90 . Un banquete en Tetlapayac toma como punto de partida el séjour de Serguéi Eisenstein en la hacienda de Tetlapayac, durante un retraso inesperado de la filmación de ¡Quéviva México! en 1931. ¡Quéviva México! fue clave en la elaboración de los conceptos de mexicanidad e identidad cultural mexicana en el siglo XX, y se basó en la imaginería de David Alfaro Siqueiros, Jean Charlot, José Clemente Orozco, Diego Rivera y José Guadalupe Posada ${ }^{3}$, al igual que en el folclore mexicano. La película de Debroise es un reenactment del episodio de Tetlalpayac de la filmación de la película de Eisenstein, cuando el director fue forzado a pasar con su equipo algunos días en la hacienda de Tetlapayac entre comida, bebida y debates.

Debroise invitó a artistas, intelectuales, críticos y curadores locales e internacionales (Laureana Toledo, Javier de la Garza, Roberto Turnbull, Thierry Jeannot, Cuauhtémoc Medina, Silvia Gruner, Dmitri Leninovich, Lutz Becker, Melanie Smith, Sarah Minter, James Oles, Enrique Ortiga, Andrea Fraser, Serge Gilbaut y Sally Stein, entre otros) a representar los papeles del equipo de Eisenstein. Mientras estos actores culturales de relevancia internacional encarnaban a sus personajes, participaron en una discusión sobre la modernidad, la política, la construcción de la mexicanidad, la obra de Eisenstein, el fin del comunismo, la relación entre estética e historia. Las discusiones en la película están ligadas a los temas centrales que permeaban el arte de los 90 incluyendo la pregunta: ¿Cómo sería un proyecto estético-político en un momento en el que el socialismo -como el contenedor de políticas progresivas- había llegado a su límite? Esto en el contexto de la insurrección zapatista, la ratificación del TLCAN y la liberalización de los mercados. Las discusiones que conforman película de Debroise hacen evidente que, al enfrentar los cambios traídos por las políticas neoliberales, las narrativas modernas de "nación" se hicieron inadecuadas e irrelevantes, y México comenzó a perder especificidad cultural. En cierto sentido, la liberalización del mercado en los albores de la globalización trajo consigo la liberalización de la identidad, de las construcciones históricas y de la hibridez-pastiche mestiza de lo postmoderno -exploradas, por ejemplo, en las obras de Rubén Ortiz Torres que encarnan "malentendidos culturales"; por ejemplo, su pintura Bart Sánchez (1991): un retrato cubista de Bart Simpson vestido de indio. Está también el video No jodas con el pasado porque te puedes embarazar (1995) de Silvia Gruner, donde la artista aborda la memoria a través del contacto corporal, dislocando construcciones sociales y estableciendo una relación escatológico-erótica con él (Medina, 1997). En paralelo a las preocupaciones exploradas en la película de Debroise y las obras de Gruner, Ortiz Torres y otros actores culturales buscaron alternativas al mecenazgo de Estado para evitar que este instrumentalizara la cultura. Como consecuencia surgieron nuevos espacios alternativos para el diálogo y la exhibición (Salón des Aztecas, La Panadería, Curare, La Quiñonera, Temístocles 44, ZONA, La Torre

${ }^{3}$ Los pintores posrevolucionarios, fundadores del muralismo y heraldos del mexicanismo que encontraron un antecedente en los grabados de José Guadalupe Posada. 
de los Vientos). Liderados por una red de artistas y críticos, los espacios exploraron nuevas sensibilidades postnacionales y neoconceptuales.

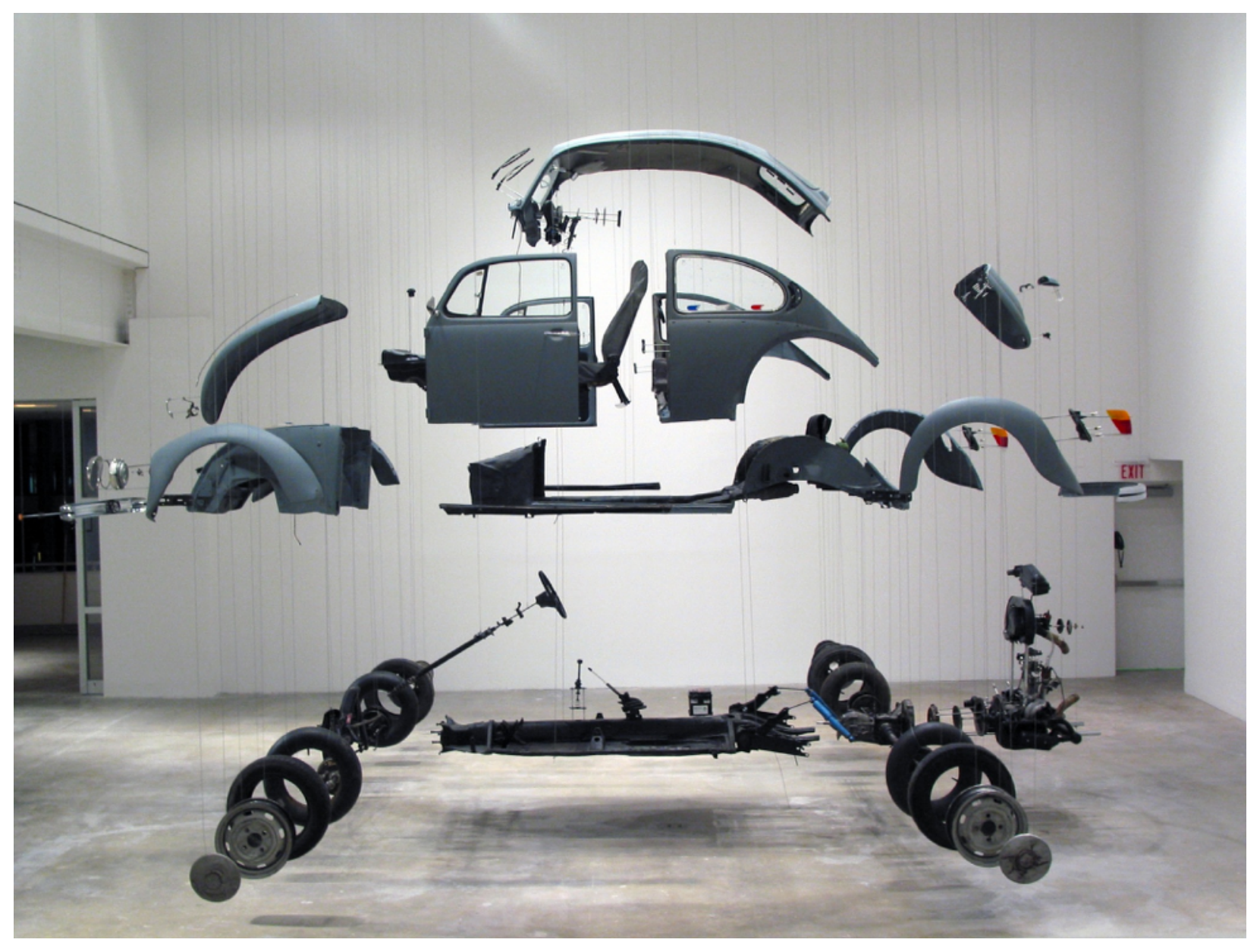

Damián Ortega. Cosmic Thing (2002)

Si tomamos en cuenta que el arte y el mundo modernos habían estado ligados al capitalismo industrial, a las ideologías de progreso y universalidad, a las sociedades disciplinarias, a una sensibilidad vanguardista (percibida en 1989 como exhausta), a la revolución y a la alternativa comunista (ambas percibidas como obsoletas también en 1989), a estados proteccionistas -que brindaban apoyo gubernamental a las artes y que comenzaron a ser desmantelados para masificar al arte en colaboración con la iniciativa privada-, podría decirse que el arte en México en la década de 1990 buscó ajustar cuentas con esta modernidad, cuya realización en el tercer mundo se percibía en extremo limitada, para muchos incluso fallida. Esto dio lugar a una veta en la producción artística que exploró las condiciones precarias de trabajo en la periferia mediante materiales baratos, gestos poéticos simples y obras efímeras. 
Ejemplos que se vienen a mi memoria son: Módulo de construcción de tortillas II (1998) de Damián Ortega; la fotografía de Gabriel Orozco, Arena sobre mesa (1992-93); el performance Algunas veces hacer algo lleva a nada (1998) de Francis Alÿs; o la fotografía Reparar de Silvia Gruner (1999); obras cargadas de preocupaciones conceptuales, situacionistas o formales que se caracterizan por ser gestos poéticos y escultóricos que resaltan lo efímero y precario de sus materiales (tortillas, arena sobre una mesa, hielo y cinta adhesiva sobre pavimento respectivamente). Cabe mencionar también la reinterpretación de la arquitectura moderna hecha por Pedro Reyes. O, mejor dicho, la revitalización del funcionalismo traducido a las nuevas formas de colectividad que surgieron a través de su revisión de las premisas sociales y políticas de la arquitectura moderna, como puede verse en Sombrero colectivo (2004), Cápulas (2002) o Zikzak (2003) (Cuevas, 2006).

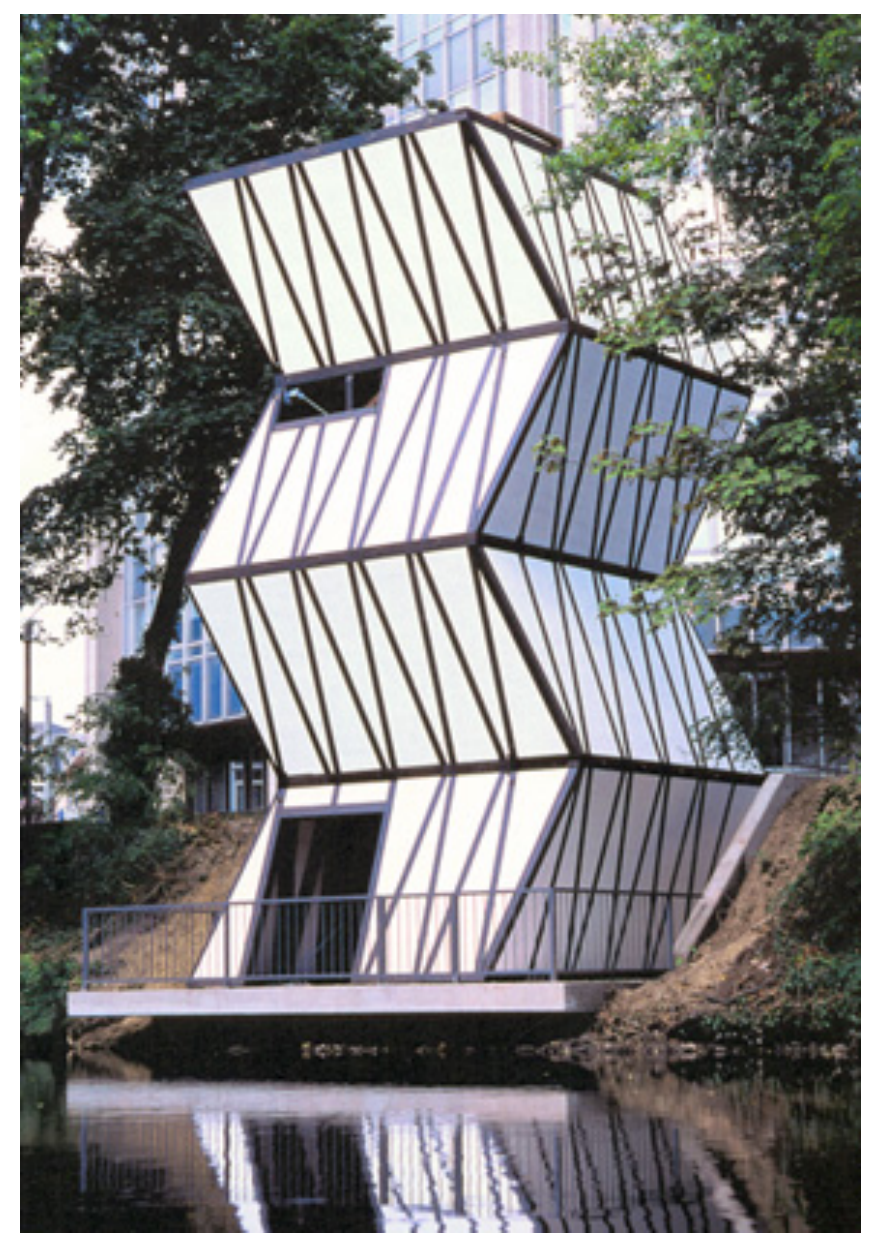

Pedro Reyes. Zik Zak (2003) 
Otras instancias que evidencian la sensibilidad de aquellos años, son las que exploraron las condiciones periféricas de su propia producción, al abordar las implicaciones de la falta de acceso directo a obras canónicas de América del Norte y Europa de las décadas de 1960 y 1970 -impensable hoy día, debido al acceso que brindan las tecnologías digitales y la profusión global de plataformas para la diseminación del arte, la teoría, la crítica y la historia-. Esta circunstancia inspiró reenactments o remakes, que no fueron parodias, sino esfuerzos para ajustar cuentas con el centro, por medio de copias para recalcar con claridad la distancia y la diferencia (Debroise, 2007: 406). Obelisco roto para mercados portátiles (1991-1993), de Eduardo Abaroa, hacía alusión a Broken Obelisk de Barnett Newman (1967), mientras Remake (1994-2003), de Daniel Guzmán y Luis Felipe Ortega, presentaba una serie de remakes de artistas clave para la historia del arte, como Bruce Nauman o Paul McCarthy. Ambos casos, basados en imágenes de libros de arte, son emblemáticos.

También se produjo obra que denotaba la "periferalidad" o las cualidades "tercercermundistas" de México. Por ejemplo, los videos de Yoshua Okón, Oríllese a la orilla (1999-2000), en los que el artista sobornó a policías para que estos se dejaran filmar mientras bailaban, contaban chistes o agitaban la macana/tocaban sus genitales, entre otras acciones. Los videos establecen una tensión cínica -que no deja de ser problemática - entre cuestiones de raza, clase y abuso de poder (hacia los policías indígenas por el privilegio masculino criollo). La volubilidad de las figuras de autoridad, como rasgo cultural, denota atraso cultural y es signo de la ausencia de un contrato social en México.

Otro ejemplo es el trabajo de SEMEFO -el colectivo del cual Teresa Margolles es miembro fundador-, que en los 90 trabajó con material obtenido, con o sin permiso, de las morgues. A través de una lógica escondida, católica y escatológica, de sacralizar los restos de cadáveres para transformarlos en reliquias-arte, el trabajo de SEMEFO alude a la impunidad, a la corrupción administrativa y a la indolencia que prevalecen en México; al igual que se refiere a las implicaciones socio-culturales de los cuerpos, en especial de aquellos que sufrieron muertes violentas (Romandía, 2011).

Un grupo de artistas que trabajó a principios de 1990 en el Taller de los viernes, respondía a los debates sobre mexicanidad y arte oficial en formas radicalmente experimentales. El grupo estuvo conformado por Gabriel Orozco, Dr. Lakra, Damián Ortega, Manuel Rocha, Laureana Toledo, Abraham Cruzvillegas y Gabriel Kuri, quienes durante casi cinco años se reunían una vez por semana para discurrir sobre preocupaciones en común y para experimentar e intercambiar ideas. Buscando espacios alternativos para exponer, lograron establecer un nuevo modelo de antiinstitución y de artistas globalizados: La Caja de zapatos de Gabriel Orozco expuesta en la Bienal de Venecia de 1993 retaba la noción misma de "artista periférico" - el título es literal y este ready made fue tirado varias veces a la basura por los guardias del espacio, quienes ignoraban el diálogo de Orzco desde la periferia con el 
aspecto duchampiano del legado del cubo minimalista. En 1999, los artistas asociados al Taller de los viernes expusieron su trabajo en la Galería Kurimanzutto (junto con otros artistas internacionales), en el Mercado de Medellín de la Colonia Roma, entre puestos de frutas y verduras. La exposición titulada Economía de mercado delineó un nuevo paradigma de gusto, marcado por la exploración y la experimentación, y estableció la figura del artista global que vive de su trabajo. Aunque la obra de los miembros del Taller de los viernes es muy diversa, artistas como Orozco, Ortega, Cruzvillegas y Kuri comparten algunas preocupaciones formales y conceptuales, tales como construcción, ensamblaje, la materialidad de los objetos orgánicos o los producidos industrialmente. También son similares en preocupaciones esculturales más clásicas (equilibrio, forma, relaciones espaciales) y en el hecho de que sus obras resultan, a veces, en bromas visuales o comentarios políticos.

En su conjunto, las narrativas sobre las promesas rotas de la modernidad, junto con la incertidumbre política y el caos de la globalización, dieron lugar a pequeños gestos o détournements de lo cotidiano a través de diversos medios. Los artistas exploraron el funcionamiento de la economía subterránea de la Ciudad de México, sus formas de trabajo, la precariedad de la clase urbana trabajadora, sus materiales de construcción y soluciones simples, las cualidades de la artesanía popular, etcétera; lo cual puede ser interpretado como enunciaciones sobre la situación social y política materializada en la dislocación de objetos de un contexto a otro. Estas alteraciones de la realidad tenían la intención crítica de politizar el espacio urbano, social, lingüístico, visual y fenomenológico. Podríamos, incluso, hablar de un tipo de espacialización del arte, que incluye un cuestionamiento a las prácticas cotidianas, la imaginación de mundos espaciales posibles, las manifestaciones materiales de lo social o del imaginario colectivo y una actualización performática de distintos órdenes y regímenes espaciales en una temporalidad actual historizante. En ese sentido, la espacialización implica también una lucha por el significado de los lugares y la desestabilización de los valores sociales y significados culturales, los cuales se tejieron en puntos de vista subjetivos y transitivos. Tal vez estos dos versos del poema "The Crush" de Mónica de la Torre, dentro de su obra Public Domain, resuman la subjetivización del espacio característico a lo que llamo la espacialización en el arte:

A point of interest is a chamber of echoes

A place is a container of places (de la Torre, 2008: 28)

Y:

What's inside if it's all exterior. Ever notice how the private never crushes the public? But how it distorts it (de la Torre, 2008: 28) ${ }^{4}$

\footnotetext{
${ }^{4}$ Un punto de interés es una cámara de ecos / Un lugar es un contenedor de lugares / Y / Qué hay dentro si todo es exterior. ¿Has visto como lo privado nunca aplasta a / lo público? Sino como lo distorsiona.
} 
Podría decirse que la espacialización en el arte llegó de la mano del desmantelamiento de la ideología universalizante moderna: la espacialidad de la ciudad, o más bien, un sentido de sitio comenzó a ganar relevancia, un sitio, sin embargo, indeterminado, dislocado y experimentado subjetivamente. En este contexto se explotó el potencial de la ciudad como espacio epistémico y, por lo tanto, como rico portador de conocimiento sensible. La capital de México se convirtió en la clave del imaginario del arte contemporáneo, una metáfora o alegoría de las cambiantes fronteras geopolíticas, con estructuras urbanas vistas desde puntos de vista subjetivos y gestos elocuentes y efímeros relacionados con realidades sociales imaginarias o transitorias. Entre las obras que lo ejemplifican están: Isla dentro de una isla (1993) de Gabriel Orozco, o su documentación-performance Hasta encontrar otra Schwalbe amarilla (1995) (aunque ninguna de las obras fue hecha en la Ciudad de México, ambas dialogan desde el punto de vista subjetivo con el paisaje urbano); la videoinstalación Atravesar las grandes aguas ¡Ventura! (1999) de Silvia Gruner, en la que plasma un paisaje afectivo interno en un recorrido por los puentes peatonales de la ciudad; el performance de Santiago Sierra, Obstrucción de una vía con un contenedor de carga (1998) (el título es literal); los videos de Melanie Smith, Ciudad espiral (2002), Tianguis II (2003) o Trilogía Parres (2004) que son tomas aéreas estilizadas de la ciudad; e incluso la instalación escultórica Visión antiderrapante de Pablo Vargas Lugo (2002), una interpretación escultórica del paisaje de ciudad hecho con pirámides de varios tamaños.

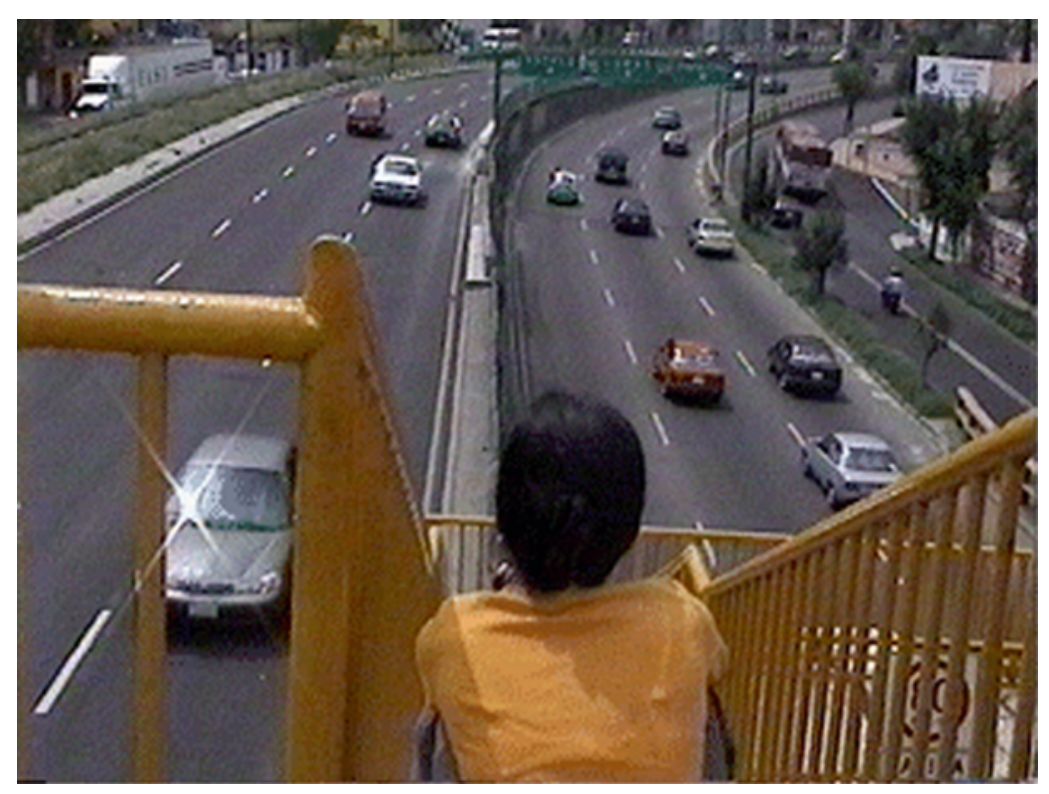

Silvia Gruner. Atravesar las grandes aguas 
Irmgard Emmelhainz. Algunas consideraciones sobre el arte en México...

Como resultado de su prominencia en el arte, la Ciudad de México sufrió un momento de exotización en dos exposiciones internacionales: Zebra Crossings, curada por Magalí Arriola (Berlín); y Mexico City: An Exhibition about the Exchange Rates of Bodies and Values (Nueva York y Berlín), las cuales-al ilustrar las consecuencias de la liberalización del mercado (violencia, caos, inseguridad, creciente desigualdad) - plantearon la vida en la ciudad como una metáfora sensacionalista. Sin embargo, en estas dos exposiciones "México" se confundía con el "arte mexicano", y ninguna de las dos pudo escapar de la enunciación del centro a la periferia, imponiendo esta narrativa a los trabajos expuestos (Montero, 2013: 217). Más tarde, México dejó de ser visto como país periférico y llegó a ocupar la delantera, no solo como laboratorio para comprender los resultados sociopolíticos de la neoliberalización, sino como el lugar donde se gestaban las vanguardias estética y literaria.

Entre los esfuerzos para promover las relaciones internacionales y atraer inversión extranjera, en la década de 1990 México implementó una política para subsidiar la educación de trabajadores cognitivos que se hicieron versátiles en la lingua franca del arte, diseño y arquitectura globales, y crearon las nuevas enclaves de sofisticación y riqueza en México. Mientras que es uno de los países más peligrosos en el mundo para los periodistas, México es uno de los mejores lugares para productores culturales. Bajo el mandato del presidente Carlos Salinas de Gortari (1988-1994) se establecieron dos organismos para apoyar la cultura: Conaculta y el Fonca. Ambos establecieron una clase media alta de trabajadores culturales, entre ellos, intelectuales, escritores, artistas, arquitectos e investigadores, entre otros, que pueden vivir cómodamente y compartir su trabajo por todo el mundo. Cuando, a principios de los 2000 el nomadismo y las prácticas "postestudio" se convirtieron en una de las condiciones de la producción estética, la escena de arte global explotó. Lo ilustran Turista (1994) y Gringo (2004) de Francis Alÿs; en ambos peformances el artista se asume como extranjero y reflexiona sobre su propia condición. O Turista maluco (1991) de Gabriel Orozco, otro performance reflexivo de la condición de nómada-turista en el que el artista acomoda naranjas para tomarles fotos en un mercado vacío en Brasil para sorpresa de los vendedores.

Explorando esta incipiente condición nómada del arte, InSite, una iniciativa de exposición binacional que tuvo lugar en la frontera entre Tijuana y San Diego, con cinco ediciones que se llevaron a cabo entre 1992 y 2005, tuvo como premisa las formas de conocimiento que pueden ser derivadas de intervenciones en dados espaciales con potencial crítico o político. La frontera se convirtió en lugar fértil para explorar los cambios y retos traídos por la economía neoliberal: trabajo en maquiladoras, cuerpos desplazados, nuevas formas híbridas en la cultura popular introducidas por la inundación de mercancía extranjera -material e inmaterial-, imaginarios e identidades. Así, InSite planteó la ciudad como laboratorio para trazar la complejidad de los cambios globales, a través de reconfiguraciones sutiles o intervenciones en el espacio urbano o en estructuras sociales. InSite concibió la frontera como 
sitio politizado de lucha, como alegoría de las relaciones globales de poder y como cuna de la política global. Obras emblemáticas producidas bajo ese marco fueron la instalación En la mitad del camino y el video Narrow Slot/Sueño paradójico (2001) de Silvia Gruner, en los que se abordan las condiciones físicas, materiales, psicológicas y lingüísticas de atravesar las fronteras; el performance de Javier Téllez, Bala perdida (2005), en la que un hombre bala atraviesa la frontera disparado desde un cañón empuñando su pasaporte; el Caballo de Troya de Marco Erre (1997), instalado en el lado mexicano de la frontera pero vacío; el performance Las reglas del juego (2001) de Gustavo Artigas en el que se juegan simultáneamente partidos de baloncesto y de fútbol en la misma cancha; y las problemáticas intervenciones de Judi Werthein [Brinco, (2005)] o Krzysztof Wodiczko [Proyección de Tüuana (2001)] (Emmelhainz, 2012), donde, de forma apolítica y sensacionalista y más bien humanitarista, se abordaron las condiciones de cruce de los ilegales hacia Estados Unidos y de trabajo de las maquiladoras, respectivamente. InSite diseminó un modelo de intervención estética en lugares públicos y estableció una plataforma para otras bienales en ciudades alrededor del mundo. El modelo consistió en invitar a artistas extranjeros a hacer intervenciones de site-specific. Este nuevo formato de exposiciones jugó un papel crucial en la transmigración del arte contemporáneo. Sin embargo, tan pronto como el lado oscuro de la globalización comenzó a ser visible (desplazamiento y desigualdad masivos, guerra y violencia, hambre, crisis financiera), el modelo llegó a su límite, ya que implicaba que artistas ajenos a la situación local intervinieran para implementar dispositivos más o menos emancipatorios o simbólicos. Esto empezó a parecerse más a paliativos o soluciones evanescentes a la devastación traída por la globalización neoliberal.

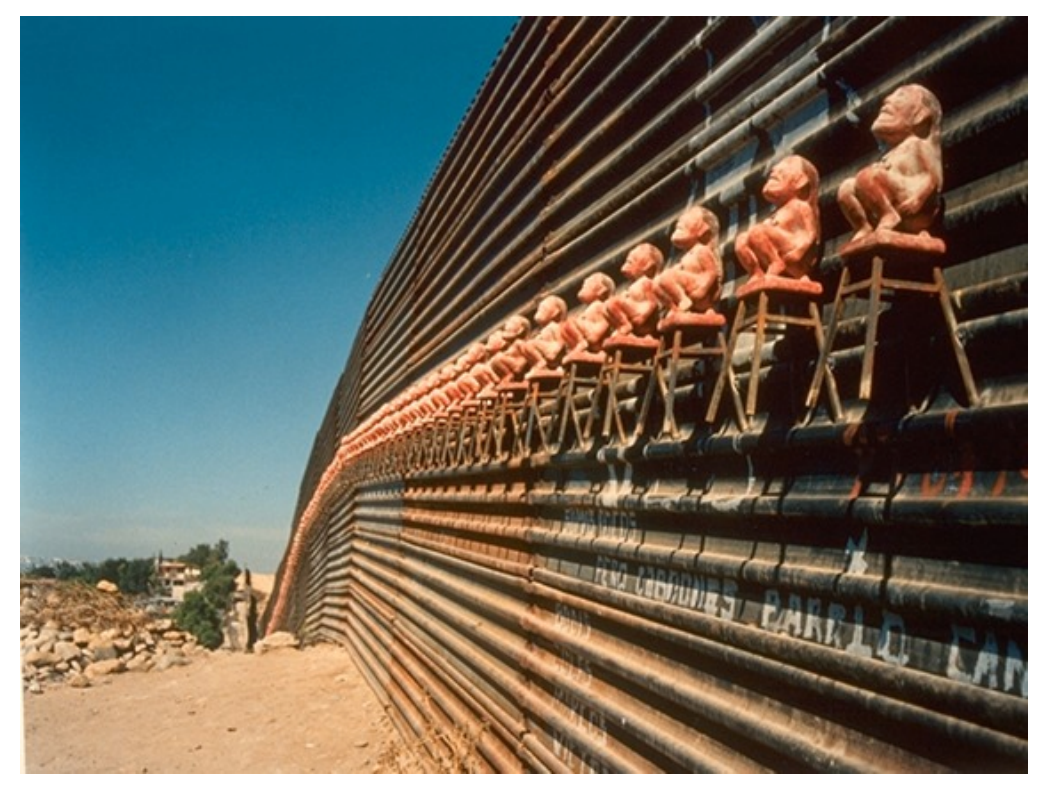

Silvia Gruner. Middle of the road 
Irmgard Emmelhainz. Algunas consideraciones sobre el arte en México...

Las limitaciones de este modelo postpolítico de intervención son cínicamente expuestas por de Renzo Martens en la película Enjoy Poverty (2006) - una crítica brutal al humanitarismo europeo en el que le adscribe a los africanos la facultad de proporcionar alternativamente gozo, y alivio de culpa a los europeos sobre las condiciones de pobreza en las que sobreviven-, y en su proyecto para producir trabajo cognitivo en el Congo, The Institute for Human Activities (activo desde 2012). Leslie Jamison también articula estos límites al describir las implicaciones éticas de ser una extranjera que camina por Tijuana en 2010, durante la cúspide de la violencia en esa ciudad:

Creo que tal vez si camino por las calles donde alguien tenga miedo, donde toda una ciudad tenga miedo, podré, tal vez, comprender un poco mejor el miedo. Esta es la gran ficción del turismo, que traer a nuestros cuerpos a un cierto lugar, hace que el lugar se acerque a nosotros o que nosotros nos acerquemos a él. Es un toque rápido de empatía. Nos la tomamos como un caballito de tequila o una línea de coca de la llave de la casa de un desconocido. Queremos que el embriagamiento de la presencia disuelva el hecho de la diferencia. Algunas veces la ciudad se deja coger en la primera cita, y a veces no. Pero siempre, siempre, nos despertamos por la mañana y nos damos cuenta de que no la conocemos para nada (Jamison, 2014: 59).

Para la década de 1990, el arte, la etnografía y el periodismo habían hecho al "Otro" transparente y la distinción colonial entre centro y periferia era ya irrelevante: la producción cultural y el capital comenzaron a celebrar la descentralización, haciendo que la distinción entre primer y tercer mundo se hiciera obsoleta. El mercado globalizado, con su habilidad para trascender las divisiones materiales integró al primer y tercer mundo, forzando así ciertas áreas del tercero a “desarrollarse”, y creando enclaves de riqueza y sofisticación cultural dentro del tercer mundo, y áreas de destitución y miseria dentro del primero. El fin del comunismo en 1989 y los discursos sobre desarrollo inherentes a la globalización, hicieron que el "tercer mundo" como categoría estético-política desapareciera, para ser sustituido por el "otro lado" (de nuestro aquí). La frontera (u otros sitios antes periféricos), se convirtió en el "otro lado", un sitio, siempre, de intervención urgente y peligro inminente, rico epistemológica y simbólicamente, pero casi nunca un lugar de lucha o cuestionamiento donde la underclass, los despojados y excluidos de los procesos globales sobreviven e condiciones precarias (favelas o cinturones de miseria, zonas desconectadas de la economía y descuidadas por el Estado, zonas de guerra antes de ser "pacificadas", etcétera). En este contexto, Reel Unreel de Francis Alÿs (2012) -un video que documenta la acción de dos niños kabulíes que bobinan y rebobinan un carrete de película por las calles de un Kabul destruido, haciendo alusión al medio del cine, pero también a un popular juego de esa región- es un signo de que el arte contemporáneo llegado a Kabul -como una sede de Documenta en 2012-, antes del alto al fuego y del arribo de los subcontratistas, es tanto paliativo como el anunciante e inseparable compañero de los procesos socioeconómicos neoliberales. 
Irmgard Emmelhainz. Algunas consideraciones sobre el arte en México...

Ha habido también casos de productores culturales que buscaron en su obra alternativas a la cartografía homogeneizante dibujada por el imperio -el aparato de gobierno descentralizado y desterritorializado que progresivamente ha incorporado al reino global dentro de sus abiertas y crecientes fronteras (Hardt y Negri, 2000: XII)-, por ejemplo la Red de Conceptualismos del Sur, una plataforma plural propuesta por mediadores culturales con el objetivo de desafiar y proponer formas más equitativas de producción y compartir conocimiento a escala transnacional, bajo la premisa de que los procesos de conocimientos "sureños" vienen de lugares, cuerpos y estéticas que pueden desafiar al imperio (Barriendos, 2006). Otro esfuerzo por trazar una cartografía alternativa al imperio es La Escuela Panamericana de Desasosiego (2003-2006) de Pablo Helguera, un proyecto de arte público que alude a los ideales panamericanos del siglo XIX -referentes a la integración americana-, a través de un viaje en automóvil desde Anchorage en Alaska, hasta Tierra del Fuego en Chile en 2006. En cada parada, Helguera instaló una escuela portátil para discutir y albergar performances alrededor del panamericanismo.

Hacia el primer lustro de los años 2000, los discursos sobre globalización habían pugnado por la superación de las divisiones geográficas, las barreras de lenguaje y las diferencias étnicas, socavando los conceptos y los ideales modernistas de nación, y de pureza étnica y formal. Dentro de este discurso, "México" pasó de ser un área geográfica, a un concepto definido fuera de su propio territorio, a través de intercambios globales provocados por la economía (migrantes, capital cultural en el extranjero, artículos de exportación como la cultura). Paradójicamente, el poder totalizante de la globalización causó una prolífica homogenización de algunos de los aspectos del modernismo, como el inglés y el arte conceptual y minimalista como linguae francae del intercambio cultural, los estilos de vida suburbanos o alternativos, las identidades étnicas genéricas y consumibles, y otros rasgos culturales: Starbucks, computadoras Apple, democracia, arquitectura neomodernista e, inclusive, el discurso de los derechos humanos. Con respecto a la homogeneización traída por la globalización, podemos evocar el trabajo de Miguel Ventura, quien a partir de 1990 estableció una crítica a la globalización del modernismo occidental, específicamente, a los aspectos utópicos del fascismo, capitalismo, psicoanálisis y abstracción, su propagación por todo el mundo y sus efectos colonizadores, consecuencia de la liberalización del mercado.

A través una institución ficticia, el "Nuevo Comité Interritorial de Lenguas" (NILC por sus siglas en inglés), Ventura construyó un proyecto ideológico con rasgos protofascistas, y un sistema de inversiones que tematizaron la producción de nuevos sujetos, alentados a producir sus propios lenguajes "universales" como una cura a la alienación y a los sentimientos de inferioridad impuestos por el colonialismo. Además, NILC es una parodia de las fuentes primarias de represión de la sociedad (las instituciones del lenguaje y la educación, así como los espacios culturales y rituales sociales), que reflejan 
misteriosamente algunos de los aspectos de la subrepticia normalización de la modernidad occidental globalizada en nuestras vidas.

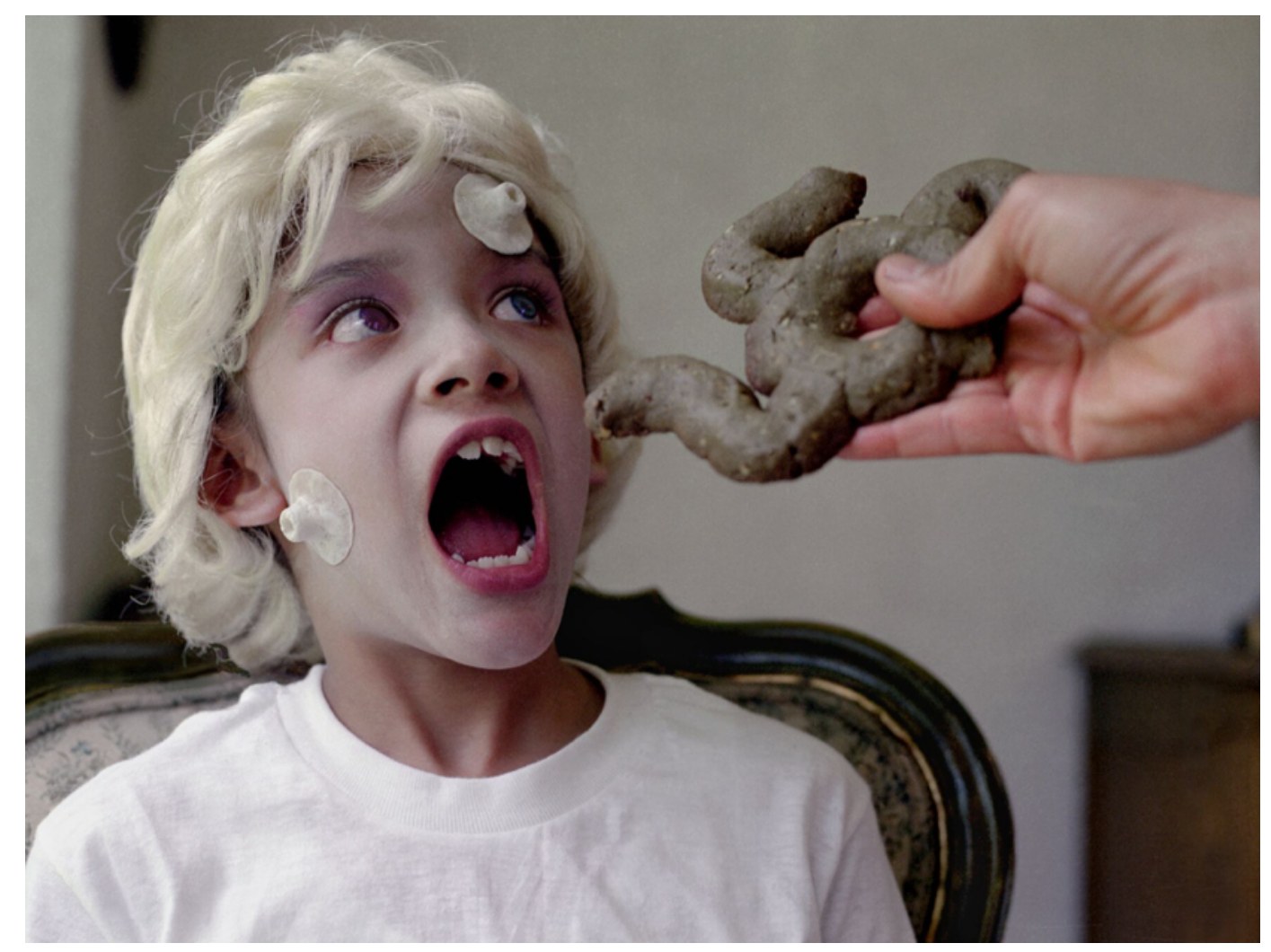

Miguel Ventura. ¿Cómo quererte mi pequeñito?(2000)

Su video How Can I Love You, My New Little One? (CCómo quererte mi nuevo pequeño?) (2000), presentado en 2001 en el marco de la exposición The PMS Dilemma en el Museo Carrillo Gil, representa un ritual de transformación de NILC que permite que el sujeto se convierta en el productor de su "propio lenguaje privado". Esto hace eco de las afirmaciones de Fredric Jameson sobre la fragmentación moderna, la cual, a su modo de ver, comenzó a astillar la sociedad, haciendo que se desarrollen lenguajes privados por grupo (étnico, económico), hasta el punto en el que cada individuo se convierte en una suerte de isla lingüística (Jameson, 1983: 136). Por lo tanto, el proyecto The PMS Dilemma de Ventura, hace una crítica a la normalización de la modernidad occidental y al inglés como lenguajes oficiales de la globalización, expresado a través de la incesante creación de lenguajes privados y expresiones idiosincráticas que homogeneizan los códigos de la modernidad y muestra la fragmentación de los lazos nacionales, comunitarios y familiares. 
El trabajo de Guillermo Gómez Peña en las décadas de 1980 y 1990, se alienó con la políticas de identidad en Estados Unidos. Sin embargo, el trabajo performático más reciente de este artista, quien trabaja desde la diáspora en California, cuestiona la desigualdad que genera el orden global, y consiste en una celebración de la migración, el nomadismo y las identidades y prácticas hibridadas; al tiempo que transmite la urgencia de articular nuevas estrategias de disidencia política, denunciar la xenofobia y las condiciones precarias de trabajo, inventar estrategias para revitalizar lazos comunitarios por medio de tecnologías como la realidad virtual, o elucidar lo marchito de las conciencias nacionales, etcétera. En su video-performance Declaration of Poetic Disobedience (2005), Gómez Peña recita un poema en el cual, a pesar de su postura liberal de denunciación del terrorismo, labra una postura discursiva para contestar y resistir al homogeneizante y devastador poder de la globalización, a la vez que se replantea las nociones de "nosotros" y "ellos", y enfatiza cómo las diferencias culturales y las posturas contestatarias subalternas se han convertido en mercancías.

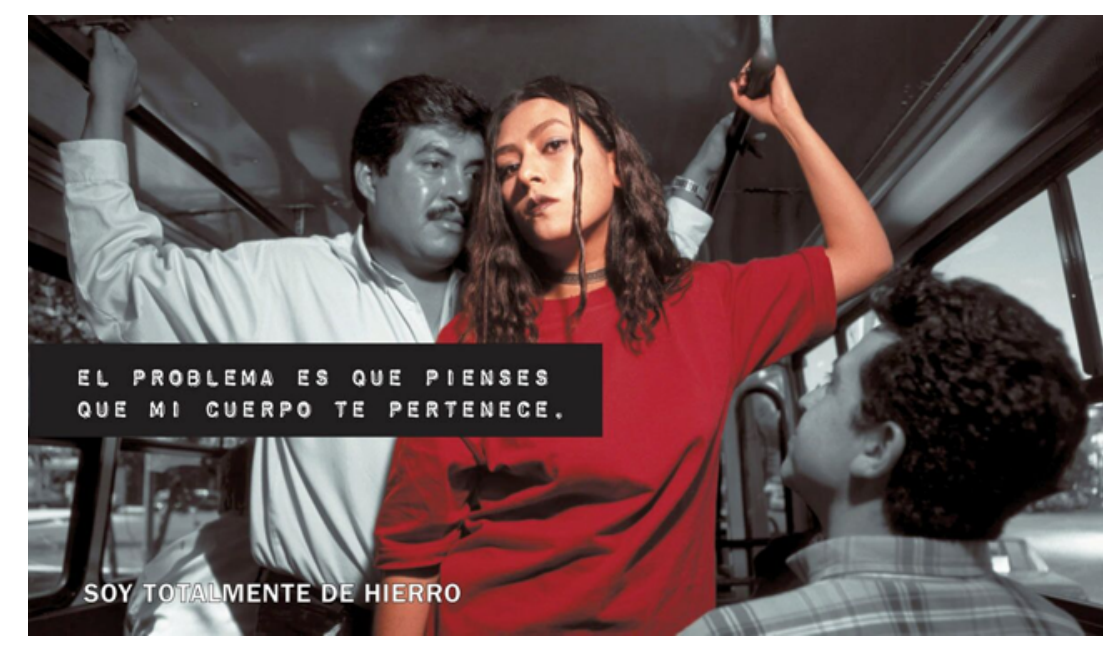

Lorena Wolffer. Soy totalmente de hierro

Tomando la cultura visual como punto de partida y dentro del linaje de artistas feministas de video y performance de los años 70, los trabajos de Ximena Cuevas, Lorena Wolffer y Minerva Cuevas comparten dos preocupaciones: la primera es elucidar cómo los medios y las corporaciones construyen imaginarios que se atrincheran en supuestos culturales; y la segunda es inventar formas para impugnarlos. Por ejemplo, los videos de Ximena Cuevas pueden ser descritos como sátiras a la cultura visual. Filtradas a través de idiosincrasias personales, distancian al espectador del espíritu melodramático de la cultura mexicana. Por su parte, el trabajo de Lorena Wolffer opera en la intersección entre arte y activismo. Al enfocarse en desestabilizar las construcciones culturales de género y al construir plataformas pedagógicas para el desarrollo colectivo de las mujeres, contraataca la 
violencia de género. Su serie emblemática, Soy totalmente de hierro, consiste en diez espectaculares que se colocaron en la Ciudad de México en el año 2000; los espectaculares parodiaban la campaña publicitaria de la tienda departamental El Palacio de Hierro, que capitaliza estereotipos de mujeres blancas de clase alta que consumen y posan, encarnando el ideal femenino hegemónico. Minerva Cuevas fundó, en 2000, Mejor vida corp., un proyecto multimedia que encarna una corporación orientada a identificar y a resolver problemas de pobreza de los residentes de la Ciudad de México. Está también Daniela Rossell, con su serie Ricas y famosas, casi un centenar de fotografías que retratan a mujeres de la oligarquía mexicana. La serie de Rossell podría describirse como un estudio etnográfico de las fantasías decadentes de la clase gobernante, encarnadas en sus mujeres, quienes posan en los interiores de sus casas. Estas imágenes expresan la contradicción inherente al hogar como un espacio "privado", contrastado con las preocupaciones "públicas" de la política de género y clase que también están en juego en las fotografías. Al darle a los sujetos fotografiados la oportunidad de construir sus propias imágenes/subjetividades visuales, las mujeres presentan sus fantasías de auto-objetización y sexualización, y se fusionan con la decoración kitsch y lujosa de sus hogares, laboriosamente mantenida por sus sirvientes, quienes algunas veces aparecen en las imágenes.

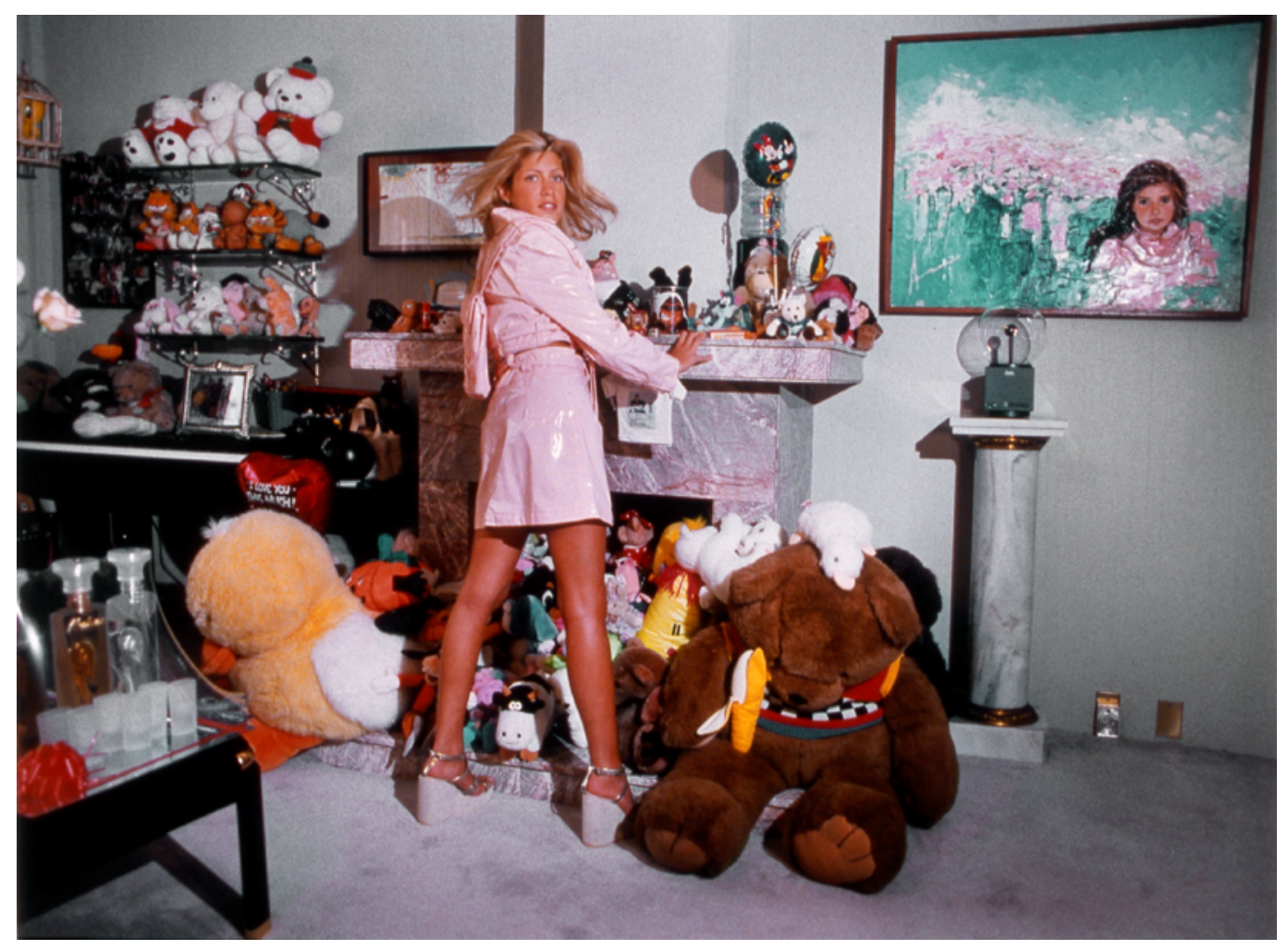

Daniela Rossell. Ricas y famosas 
Irmgard Emmelhainz. Algunas consideraciones sobre el arte en México...

Rossell ha sido asociada a la "generación XX" junto con artistas como Miguel Calderón, Yoshua Okón, Carlos Amorales, Artemio, Pablo Helguera, Minerva Cuevas, Claudia Fernández, Gustavo Artigas, Daniel Guzmán, Richard Moszka, Luis Felipe Ortega, Sofía Táboas, Diego Toledo, Jonathan Hernández, Pedro Reyes y Vicente Razo. Todos ellos exhibieron en La Panadería (fundada en 1994 por Calderón y Okón) (Acosta Romero, 1999) y su trabajo fue descrito por Pablo Helguera como un híbrido entre la modernidad mexicana y referencias históricas globales del pop y de la historia del arte (Helguera, 2005: 72). Por ejemplo, Miguel Calderón usó la cámara para manipular su propia imagen como un frente ante la cambiante identidad social y política mexicana. Calderón compartió con Okón y Amorales una postura cínica ante la fatal aparición de la globalización, la cual llegó a México junto con una economía de la explotación, y una denigración de las condiciones de vida y de trabajo de los ciudadanos. Por ejemplo, la serie de fotografías de Calderón (1998), en la cual custodios del Munal (Museo Nacional de Arte) posan emulando las pinturas albergadas en el museo, evidencia cómo, a pesar de ser subsidiada por el Estado, la clase trabajadora está lejos de la "alta cultura", y alude, indirectamente, a cuestiones de clase y raza. En Flames Maquiladora (2001-2002) de Carlos Amorales, el público estaba invitado a cortar plástico rojo para manufacturar botas para luchadores de lucha libre; las botas se vendieron después como obras de arte (la instalación incluía letreros que advertían: “¡Trabaja por diversión! ¡Trabaja para mí!”). Para All Employees (2002), Yoshua Okón visitó restaurantes de la cadena Carl's Jr. en Los Ángeles para filmar videos donde los empleados se presentaban detrás del mostrador, como si lo hicieran para un cliente. Después, Okón empalmó los videos convirtiendo imagen y audio en una masa abstracta proyectada detrás de un mostrador a escala real. Lo que tienen en común estas obras es que subrayan la relevancia de las nuevas o viejas formas de trabajo para mantener a la economía global, mientras hacen imperceptibles las condiciones laborales bajo el neoliberalismo.

En esta misma línea cínica, la obra de Santiago Sierra subraya e invisibiliza las condiciones de trabajo neoliberales, yuxtaponiendo cuerpos que están más deteriorados que otros y que han sido desarraigados y despojados. Sierra los confronta con otros cuerpos más privilegiados en museos, galerías y bienales [Obreros remunerados para permanecer dentro de cajas de cartón (2000) o Pared cerrando un espacio (2003)]. En su obra, el trabajo remunerado es explotado en tres niveles: por la maquinaria que evidencia su vulnerabilidad, al estar al servicio del cinismo del artista y por estar al servicio del goce estético de la clase privilegiada. El cinismo y ambivalencia que caracterizan esta línea de trabajo, pueden ser adscritas a la "condición-postcomunista", de la cual deriva la formalización de la desilusión revolucionaria traída por el fallecimiento de la utopía comunista moderna. De acuerdo con la narrativa que le subyace al arte de vanguardia, los trabajadores podrían emanciparse de la tiranía del trabajo y de la burguesía. Este posible futuro, sin embargo, fue truncado por el hecho de que el 
Irmgard Emmelhainz. Algunas consideraciones sobre el arte en México...

comunismo tuvo lugar como un evento en la historia actual y fracasó tanto en términos ideológicos, como en prácticos. Con el arte contemporáneo cínico, la alienación traída por la sociedad de consumo no aparece como algo problemático, ni tampoco la profundización de la desigualdad y el desempleo, al tiempo que contribuye a la normalización de la proliferación de la vulnerabilidad.

Otra sensibilidad que puede ser descrita como "postcomunista", se manifiesta en obras gestadas en acciones inútiles que no llevan a nada. 500 Kilos de impotencia o posibilidad (1995) y Away from Үои (2001), de Silvia Gruner, están basadas en tareas imposibles condenadas a repetirse eternamente sumergir con una grúa un collar de 500 kilos en la bahía de San Diego y nadar en la misma dirección repetidamente-. Están también A Kilometer (2004) o Untitled (Damage and Reparation) (2005) de Enrique Ježik, que consisten en ejecutar agresiones pasivas inútiles que involucran maquinaria pesada.

Paradojas de la praxis de Francis Alÿs, por su parte, es una serie de acciones poéticas donde el artista hace trabajos claramente fútiles que pueden, o no, convertirse en comentarios de situaciones sociopolíticas. En la Paradoja más reciente, Paradox \#5: A veces soñamos como vivimos y a veces vivimos como soñamos, Alÿs patea un balón en llamas por las calles de Ciudad Juárez, urbe que se ha sido declarada "la más violenta del mundo". Al basarse en gestos inútiles repetidos al infinito, las obras operan en un presente perpetuo que evoca una postura en espera a la que nada puede seguirle.

Artistas como Edgar Orlaineta y Carla Herrera-Prats -asociados con Art Deposit, un espacio fundado en 1996 por Stefan Brüggemann, Iñaqui Bonillas y Ulises Mora-reinterpretaron estrategias artísticas modernas, conceptuales y minimalistas para direccionar problemas sociopolíticos [RemesasSending Money Back (2003), de Carla Herrera-Prats), que aborda la arquitectura que alberga los flujos de dinero de los migrantes a sus lugares de origen]; preocupaciones personales [Iñaqui Bonillas, J.R. Plaza Archive (2003), un archivo de referencias literarias, filosóficas y visuales a partir de un archivo de fotografías del abuelo del artista]; o para producir posturas conceptuales críticas como en el trabajo de Brüggemann [Naked Girl (2003) o Show Titles (2000-)].

Están también los traslados del readymade a metáforas visuales y marcadores espaciales [Untitled (2003) del artista Diego Teo]; la transposición del site-specific a la comunidad como en el trabajo social de Antonio Vega Macotela, Time Exchange (2006-2010) con prisioneros; o de Claudia Fernández [Proyecto Meteoro (2002-al presente)] con niños de la calle.

La exploración de los componentes del capitalismo tardío como política, territorio, tiempo e intercambio, se presentan a través de estrategias conceptuales en la obra de Julieta Aranda [You Had No Ninth of May (2008)], o la investigación arqueológica de Mariana Castillo-Deball del rol que tienen los 
objetos en nuestra manera de entender la historia y cómo pueden entregar nuevas conexiones y significados [Stelae Storage (2013)].

Algunos artistas que pertenecen a esta generación, volvieron a trabajar con la preocupación de los 90 por el espacio público y la espacialización del arte, pero borraron la cualidad de interior o exterior de lo público, inherente a la producción artística. En otras palabras, los artistas reflexionaron sobre sitios localizados temporalmente, subrayando cómo, frente a la privatización desenfrenada de todo, su estatus como público o privado ya no era importante. Un ejemplo es la intervención Paracaidista, Av. Revolución 1608 de Héctor Zamora en el Museo Carrillo Gil (2004), para la cual el artista levantó una precaria estructura habitacional a partir de la autoconstrucción, técnica para edificar popularmente usada en barrios marginales. El estatus ambivalente del carácter público o privado del espacio fue señalado por el artista, quien habitó por tres meses el espacio; apuntó así a la incipiente privatización de los fondos para el arte (Hernández y Gurfinkel, 2013). Para el performance Un día de trabajo (2007) de Marcela Armas, la artista pidió a diez asistentes médicos del IMSS (Instituto Mexicano del Seguro Social) que portaran un enorme uniforme que los mantenía unidos mientras hacían sus tareas cotidianas. En el performance, entran en tensión los intereses privados, los deseos colectivos y la necesidad de negociarlos en nombre de la eficiencia, conectando la exterioridad social con el trabajo burocrático en el

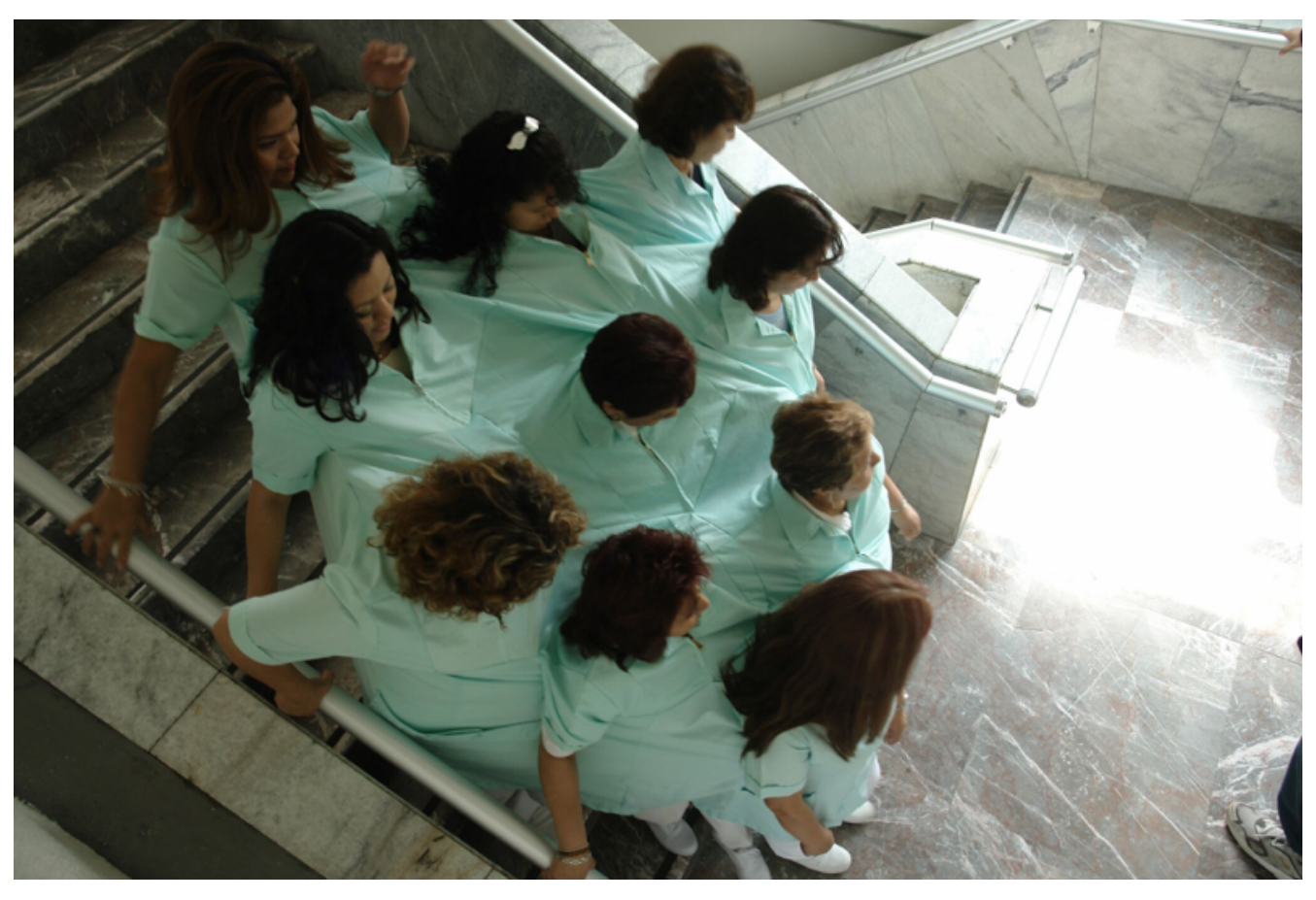

Marcela Armas. Un día de trabajo 
interior de las instituciones. Por otra parte, en La solución somos todos (2011), Diego Berruecos escarba, a través de su archivo visual, la historia visual del PRI, recalcando cómo la política se traduce en el lenguaje, en el paisaje, en la cultura visual, en la memoria colectiva y en la arquitectura. El artista cuestiona cómo estas manifestaciones sensibles se han convertido en parte de la cultura mexicana. Su omnipresencia material y sensible es la base del gusto y de una sensibilidad ideológica inconsciente.

Dentro de las línea de la crítica institucional, el museo se convirtió en el medio del arte sujeto a la tradición moderna de la reflexividad. En esta línea de trabajo, Pablo Helguera propuso a la institución de arte (conformada por relaciones sociales, discursos, un espacio físico) como medio y como tema de su trabajo. En el simposio que organizó en 2002 (El museo como medio) examinó el legado de la crítica institucional. También lo hizo en sus libros Contemporary Art Style Manual (2007), en los dos volúmenes de Artoons (2009), caricaturas sobre el mundo del arte; y en su blog The Estheticist (2010-2011).

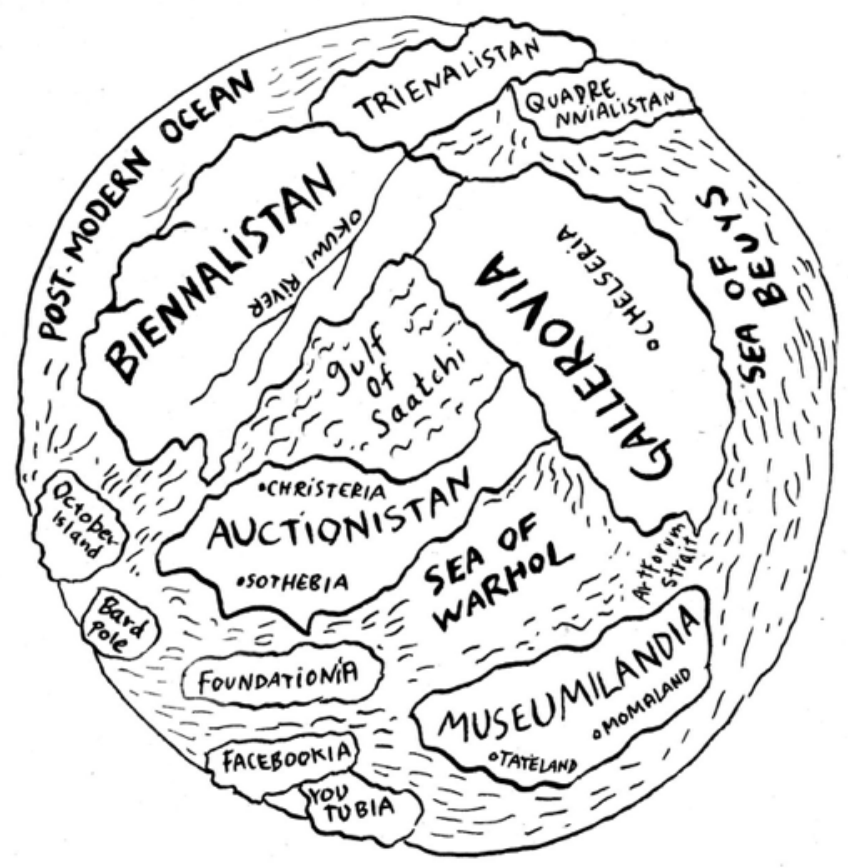

Pablo Helguera. Biennalistan 
Irmgard Emmelhainz. Algunas consideraciones sobre el arte en México...

El trabajo de Mario García Torres, en cambio, se basa en historias secretas o rumores de la historia del arte y el cine, los cuales traduce a videos, libros, exposiciones, vitrinas o postales. Analizando el linaje y la paternidad en la historia del arte, García Torres ha revisitado a artistas como Robert Barry, Alighiero Boetti o el Dr. Atl para investigar los mecanismos que hicieron posible que su trabajo se convirtiera en arte, explorando el sistema que apoyó sus narrativas. Otras formas de crítica institucional son Art Film I: Ever Present, Yet Ignored (2006), un video reflexivo y burlón sobre los dilemas que se plantean los artistas jóvenes, y Banana Peel (2008) (literal: una cáscara de plátano tirada en el New Museum en Nueva York) de Adriana Lara, o las obras de Tercerunquinto y Débora Delmar, quienes elucidan en su trabajo los arreglos espaciales de las instituciones y sus colecciones y archivos, sus implicaciones políticas y la condición de mercancía de lujo del arte respectivamente.

Estas formas de crítica institucional podrían parecer conservadoras comparadas con el proyecto de Miguel Ventura, Cantos cívicos (2008-2009), instalación con la cual se inauguró el Museo Universitario de Arte Contemporáneo (MUAC). La exposición vanguardista-kamikaze esbozó una analogía entre 1929 y 2008, como años que marcaron los inicios de crisis financieras, así como inauguraron eras de racismo y xenofobia. Dentro de una gran estructura que parodiaba la starchitecture de los museos contemporáneos, Ventura escenificó la transformación de NILC en un régimen fascista. La estructura albergaba en su interior una gran colección de parafernalia nazi, un bioterio para ratas, túneles y collages gigantes que incluían suásticas entrelazadas con signos de dólar, retratos de soldados estadounidenses caídos en la guerra de Iraq, pornografía gay y heterosexual, imágenes de desechos fecales, una colección de muñecas étnicas jerárquicamente acomodadas (las blancas hasta arriba y las negras abajo), imágenes de la sección de sociales de un periódico nacional, todo esto presidido por Milton Friedman siendo alimentado por mierda que fluye de una cuchara de plata. La instalación de Ventura dibujó una analogía entre el nazismo de la década de 1930 - como un aparato sensible cultural y social que existió para legitimar la exterminación del otro racial e ideológico- y los lazos del arte contemporáneo a la oligarquía neoliberal mundial como medio para legitimar o oscurecer los procesos de despojo, destrucción ambiental, exterminación y de profundización de la desigualdad en curso.

La transmigración constante de artistas alrededor del mundo, que tienen la Ciudad de México como epicentro, atestigua el hecho de que México se ha consolidado como un lugar crucial para la producción y circulación del arte contemporáneo global. Este campo ha expandido sus operaciones para trascender las divisiones entre los espacios alternativos y los institucionales, privados y públicos, mientras que nuevos agentes continúan surgiendo en el contexto de un floreciente mercado del arte, exposiciones y espacios de producción y educación. Esto se ha logrado a través de una combinación de financiamiento del Estado y de corporaciones privadas con políticas específicas para apoyar y exportar la producción cultural. Por ejemplo, la colaboración del Estado con el mercado del arte, al invertir en la 
feria Zona MACO -no solo comprando, sino también cubriendo los viáticos de directores, curadores y galeristas de museos internacionales- e implementando un programa oficial para guiar el desarrollo simbólico y satisfacer la demanda de mercancías creativas y el apetito por objetos de lujo (González Rosas, 2012).

Hacia el primer lustro de la primera década del siglo XXI, la búsqueda por espacios de exposición y diálogo alternativos -que había sido una preocupación en la década de 1990- se había convertido en trabajo de legitimación, logrado a través de la ruptura o contestación de discursos y prácticas preestablecidos, a través de estrategias de marketing y tejiendo redes con ciertos discursos dentro de la institución de arte y creando espacios o prácticas alternativas. Un ejemplo de ello es la exposición La era de la discrepancia: Arte y cultura visual en México 1968-1997 que tuvo lugar en 2007 en el MUCA de la UNAM. Desde el punto de vista de la legitimación académica e histórica, la exposición buscaba construir una narrativa de la plástica del México moderno, postulando una genealogía del arte contemporáneo en el cual la utopía modernista se traslada a una modernidad local que entra en crisis con la demanda y represión del movimiento universitario en 1968. En esa narrativa, el 68 inauguró una era en el arte mexicano donde los artistas afirman su derecho de estar en desacuerdo con los cánones dictados por las instituciones, el mercado y el gusto convencional promovido por la industria cultural. La exposición planteó la "discrepancia" como una opción sana y no violenta ante el autoritarismo, y al arte como un campo propio en el cual las sociedades pueden analizar, cuestionar y corregirse a sí mismas para deshacer las "tentaciones de autoritarismo". En esta narrativa, la crisis de la modernidad fue seguida por el luto al fracaso de la modernización del México de los años 90, que precede una nueva era "democrática" neoliberal, en la cual las instituciones culturales son consolidadas como contenedoras de disidencia, otorgando al arte (de una sensibilidad corporativa en aumento) una función de desacuerdo, revelación, shock o de cinismo normalizante. En ese sentido, la UNAM se convirtió en centinela de la tradición disidente del arte moderno, especialmente desde que resguarda el MuAC, inaugurado en 2008, que alberga una colección de arte desde 1968. Por lo tanto, la Universidad se ha convertido en el último bastión que queda de pie ante el menguante sistema educativo mexicano y en el contenedor oficial de descontento simbólico (de clase urbana media, no indígena) financiado por intereses corporativos. La corporativización del arte va en aumento a través del mecenazgo de simposios, proyectos, exposiciones, becas, publicaciones y la presencia de miembros de mesas directivas en museos públicos, representando intereses del poder corporativo, dando vía libre a la lenta transferencia del capital cultural al sector corporativo. Además, en los últimos diez a 15 años, surgió una clase creativa para darle vida a ciertas áreas en la Ciudad de México en las cuales las galerías, panaderías gourmet, hoteles boutique, tiendas de diseño, despachos de arquitectura, estudios de artistas visuales, etcétera, han proliferado, resaltando los lazos entre la economía de las bienes raíces y el mercado del arte. 
Irmgard Emmelhainz. Algunas consideraciones sobre el arte en México...

Esta transformación cultural ha sido marcada también por dos filántropos que han erigido museos en una antigua zona industrial en la Ciudad de México conocida como Nuevo Polanco, poblado de rascacielos que alojan corporaciones trasnacionales, así como casas y oficinas de lujo. La filantropía populista del Museo Soumaya se ve reflejada en la mediocre calidad de su universalizante colección, mientras que el Museo Jumex encarna la alta cultura corporativa al coleccionar arte contemporáneo internacional: desde el minimalismo hasta el arte joven global. Los dos museos reflejan los intereses de las compañías que los patrocinan -la reciente cancelación de la exposición de Hermann Nitsch en el Museo Jumex es un ejemplo de esto (Burnett, 2015) ${ }^{5}$, así como los gustos de sus dueños, a quienes les sirven como instrumento de relaciones públicas y de marketing, mientras que buscan supuestamente contribuir al "capital humano" del país.

En este panorama, es difícil pensar en un horizonte de autonomía crítica. El arte en particular y la cultura en general no son adyacentes al Estado, las corporaciones y los medios, sino que son la maquinaria central de la administración de consenso e instrumento principal de canalización de antagonismo. Además, hay que tomar en cuenta que el contexto mexicano está imbricado en los procesos globales y que, por lo tanto, está perdiendo su lógica de la especificidad. Como consecuencia, nos estamos enfrentando a problemas y a retos análogos a otros países que no están necesariamente en el sur. Lo que distingue al arte contemporáneo del moderno es que, hoy en día, el arte y la cultura están en el grueso de los procesos neoliberales: no solo la cultura en general y el arte contemporáneo en particular son brazos del poder, sino que el Estado y las corporaciones invierten en ellos porque los consideran como fuentes de plusvalía, crecimiento económico, y paliativos a los estragos causados por las políticas neoliberales en el tejido social. Específicamente, la institucionalización y a la incorporación del arte mexicano a la economía global tuvieron lugar con la ayuda de fondos públicos y privados, habiendo institucionalizado y mercantilizado el modelo de la ruptura, el cual implica hacer trabajo de legitimación de arte y artistas obras pero fuera de las instituciones y con un filo crítico hacia ellas.

Los verdaderos problemas aquí tienen que ver, primero, con la obsolescencia e inefectividad de la crítica ante los problemas que encaramos; y segundo, con el hecho de que el arte dejó de designar un reino de reproducción o representación, para convertirse en un campo de producción y poder social y económico. La autonomía del arte, por lo tanto, se ha vuelto un problema, no porque no legitime cualquier cosa como arte o a cualquiera como artista, sino porque es un campo para la producción de plusvalía. Asimismo, el mundo del arte es parte de una economía de especialización y producción de

\footnotetext{
${ }^{5}$ Un grupo de activistas preocupado por los derechos de los animales presionó al Museo Jumex en marzo de 2015 para cancelar la exposición de Hermann Nitsch, accionista vienés conocido por usar restos de animales en su trabajo. La decisión de cancelar la exposición cediendo a la petición de estos activistas fue tomada desde el corporativo Jumex, que impuso su decisión sobre el director, el curador y el consejo del museo, lo que fue un claro ejemplo de la falta de autonomía de las instituciones culturales y su sujeción a los intereses corporativos.
} 
relaciones sociales que se materializan en exposiciones, conferencias, residencias, vernissages, homenajes, fiestas y presentaciones VIP. Los lazos y las redes que se crean son más importantes que los trabajos o proyectos por sí mismos. El mundo del arte es un contexto y una red social de distribución. Al mismo tiempo, el arte contemporáneo es un parque de diversiones para el 1\%, y tiene la función de embellecer al capitalismo. Es por esto que el arte contemporáneo es indisociable de la precariedad, exploración, despojo, explotación, de la guerra contra el crimen organizado y de las burbujas de bienes raíces. Si el arte contemporáneo condensa artísticamente los procesos económicos de la globalización en un intento por comprender el presente, necesitaría comenzar a tomar en cuenta una crítica ideológica, al igual que su complicidad con procesos de la producción capitalista tardía. 
Irmgard Emmelhainz. Algunas consideraciones sobre el arte en México...

\section{Bibliografía}

Acosta Romero, Jimena (1999). La Panadería, 1994-1996: Un fenómeno sociológico, estético y generacional. Tesis de licenciatura en Historia del Arte, México D.F.: Universidad Iberoamericana.

Barriendos, Joaquín. "Micropolitics of the Archive. Part I: Southern Conceptualisms Network and the Political Possibilities or Microhistories”. Field Notes 02, (2006): Hong Kong: Asia Art Archives.

Berg, Edgardo Horacio (2004). "Fuera de la ley". Rodríguez Pérsico, Adriana (comp.) Ricardo Piglia: Una poética sin límites. Pittsburgh: Instituto Internacional de Literatura Iberoamericana: 213-222.

Burnett, Victoria. “Museo Jumex Cancels a Hermann Nitsch Show”. New York Times, 24 de febrero de 2015.

Cuevas, Tatiana. “Interview with Pedro Reyes”, Bomb 94 (Invierno de 2006).

De la Torre, Mónica (2008). “Crush,”. Public Domain. New York: Roof Books.

Emmelhainz, Irmgard (2012). "La geo-est(é)tica en la era del imperio: de subalternos, cosmopolitas y guerras culturales”. Alotropías en la trinchera evanescente: arte y geopolítica en la era de la guerra total. Puebla: BUAP.

González Rosas, Blanca. “Arte: Zona MACO y los invitados de Conaculta”. Proceso, abril 19, 2012.

Hardt, Michael y Negri, Antonio (2000). Empire. Cambridge, Mass: Harvard University Press.

Helguera, Pablo. "La generación XX y su doble encrucijada” Exit Mexico ed. Rosa Olivares (2005).

Hernández, Edgar Alejandro y Gurfinkel, Inbal Miller (2013). Sin Límites: Arte contemporáneo en la ciudad de México 2000-2010. México D.F.: Promotora Cubo Blanco A.C.

Jameson, Frederic (1983). "Postmodernism and Consumer Society". The Anti-Aesthetic: Essays on Postmodern Culture. New York: The New Press.

Jamison, Leslie (2014). The Empathy Exams. New York: Graywolf Press.

Kwon, Miwon. "Questionnaire on the Contemporary". October 130 (Fall 2009), 15-18.

Medina, Cuauhtémoc. “Irony, Barbary, Sacrilege”, trad. Ellen Camus. Zonezero (1997).

Medina, Cuauhtémoc y Debroise, Olivier (2007). La era de la discrepancia arte y cultura visual en México 1968-1997. México D.F.: MuAC.

Montero, Daniel (2013). El cubo de Rubik, arte mexicano en los años 90. México DF: Fundación Jumex Arte Contemporáneo. 
Irmgard Emmelhainz. Algunas consideraciones sobre el arte en México...

Osborne, Peter. "The Postconceptual Condition or, the Cultural Logic of High Capitalism Today". Radical Philosophy 184 (March/April 2014), 23-30.

Romandía, Ana. “SEMEFO 1990-”, Artes e historia de México (Octubre 2011). 